\title{
Nasal Tip Dermoid Sinus Cyst Excision by Open Rhinoplasty Technique
}

\author{
Pirabu Sakthivel $^{1}$ Rajeev Kumar ${ }^{1}$ Arvind Kairo ${ }^{1}$ Rakesh Kumar ${ }^{1}$ Ramya Thota ${ }^{1}$ \\ ${ }^{1}$ Department of Otorhinolaryngology and Head-Neck Surgery, \\ All India Institute of Medical Sciences, New Delhi, India \\ J Child Sci 2017;7:e10-e13.

\begin{abstract}
Address for correspondence Pirabu Sakthivel, MS, DNB, ENT, Department of Otorhinolaryngology and Head-Neck Surgery, All India Institute of Medical Sciences, Ansari Nagar, New Delhi 110029, India (e-mail: pirabusakthivel@gmail.com).
\end{abstract}
Abstract
Keywords
- dermoids
- nasal sinuses
- open rhinoplasty

Nasal dermoid sinus cysts are uncommon congenital anomalies, presenting either as cysts or sinuses with varied presentation at birth, childhood, or even adulthood. A midline nasal pit, fistula, or infected mass may be located anywhere from the glabella to the nasal columella. Preoperative radiological investigation with CT (computed tomography) and MRI (magnetic resonance imaging) scans is mandatory to rule out intracranial extension. Complete excision of the cyst along with its tract is the only definitive therapeutic modality. We present a case of nasal dermoid sinus cyst in a 3-year-old male child who underwent excision by open rhinoplasty approach.

\section{Introduction}

Nasal dermoid sinus cysts (NDSCs) are uncommon midline developmental anomalies with an estimated incidence of $1: 20,000$ to $1: 40,000$ births. ${ }^{1,2}$ NDSCs are distinct from dermoids in other regions; they may have an intracranial extension, requiring careful interventional strategies. These lesions can be present anywhere in midline, as sinus or cyst, from glabella to columella, with glabella being the most common site. Intermittent secretion of cheesy offensive material on manipulation and recurrent infections are frequently observed. Hairy outgrowth from the sinus opening, if present, is pathognomonic, but is found in less than half of the patients. ${ }^{1,3}$ Preoperative radiological investigation with CT (computed tomography) and MRI (magnetic resonance imaging) scans is mandatory to rule out intracranial extension. All in all, complete excision of the cyst along with its tract is the only definitive therapeutic modality.

In this study, we report a case of NDSC in a 3-year-old male child who underwent excision by open rhinoplasty approach.

\section{Case Report}

A 3-year-old male child presented to our department with a chronically discharging sinus at the tip of the nose. The sinus had been noticed since 1 year of age and there was no other complaint. On examination, there was a $2 \times 1 \mathrm{~cm}$ diffuse swelling on the dorsum of nose with opening of the fistula at the nasal tip (-Fig. 1). On pressing the swelling, whitish material came out of the sinus. There was no increase in size of the swelling while crying or coughing. Anterior rhinoscopy revealed fusiform septum; however, rest of the examination was normal. A nose and paranasal sinus CT scan and sinogram showed a cyst without intracranial extension, with a single tract going under the nasal bones and a bifid crista galli (-Fig. 2). We performed an open rhinoplasty under general anesthesia (-Fig. 3). The tract was continuing with the cyst, which elongated cephalically between the separated nasal bones. The fistulous tract and the cyst were excised without rupturing. After complete removal of the cyst and tract, interdomal sutures were applied, and the specimen (-Fig. 4) was sent for pathological examination. The postoperative period was uneventful, and the child was discharged next day. The postoperative pathology report was suggestive of a dermoid cyst. The child had no complaints on 2-year follow-up, and esthetic result was satisfying, except for minimal saddle nose (-Fig. 5).

\section{Discussion}

Nasal dermoid is the most common congenital midline lesion constituting 1 to $3 \%$ of all dermoids and 4 to $12 \%$ dermoids in

Copyright @ 2017 Georg Thieme

Verlag KG Stuttgart · New York
License terms

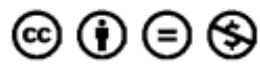

March 25, 2017

accepted after revision

May 24, 2017
DOI https://doi.org/

10.1055/s-0037-1604023. ISSN 2474-5871. 


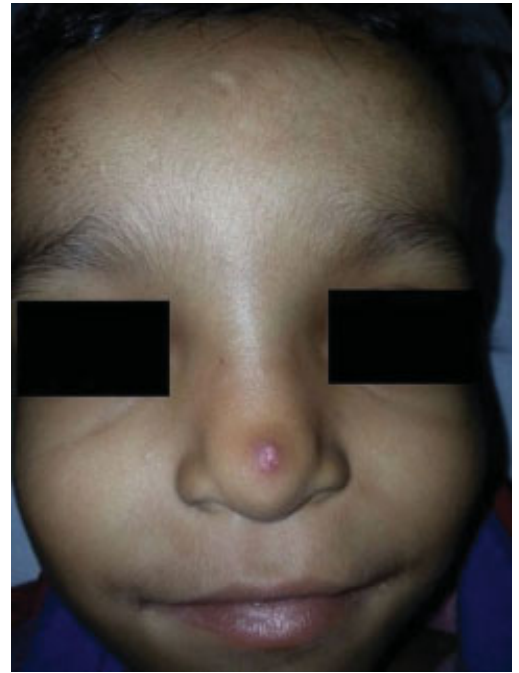

Fig. 1 Clinical appearance.

head and neck, ${ }^{4-7}$ with a male preponderance. ${ }^{5}$ NDSCs usually occur sporadically, but familial cases have also been reported. ${ }^{8,9}$ Although no syndromic association has been reported, they can coexist with numerous craniofacial

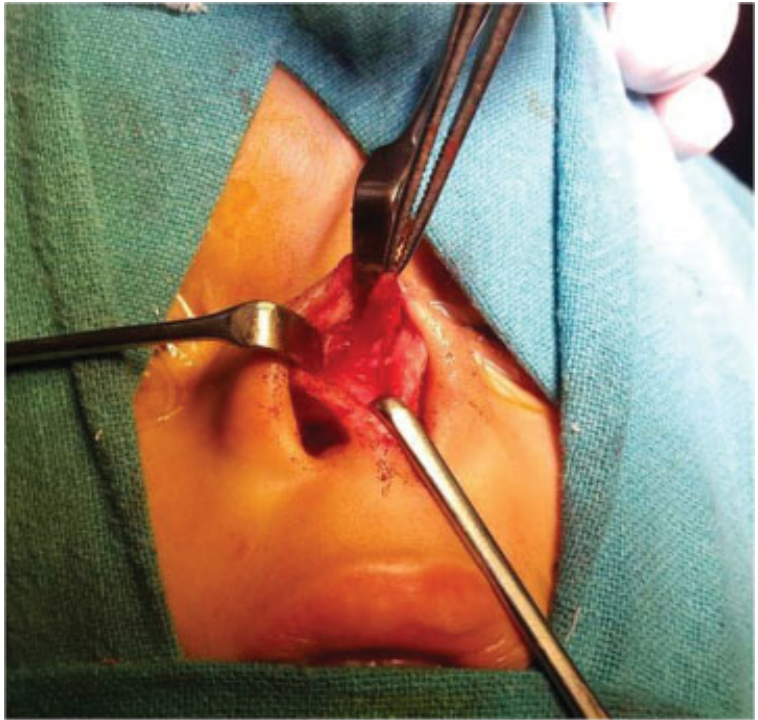

Fig. 3 Open rhinoplasty with delineation of the sinus tract.

anomalies such as hypertelorism, cleft palate, hemifacial microsomia, aural atresia, pinna deformities, branchial sinus anomalies, and even cardiac, genital, and gastrointestinal anomalies. $^{10}$

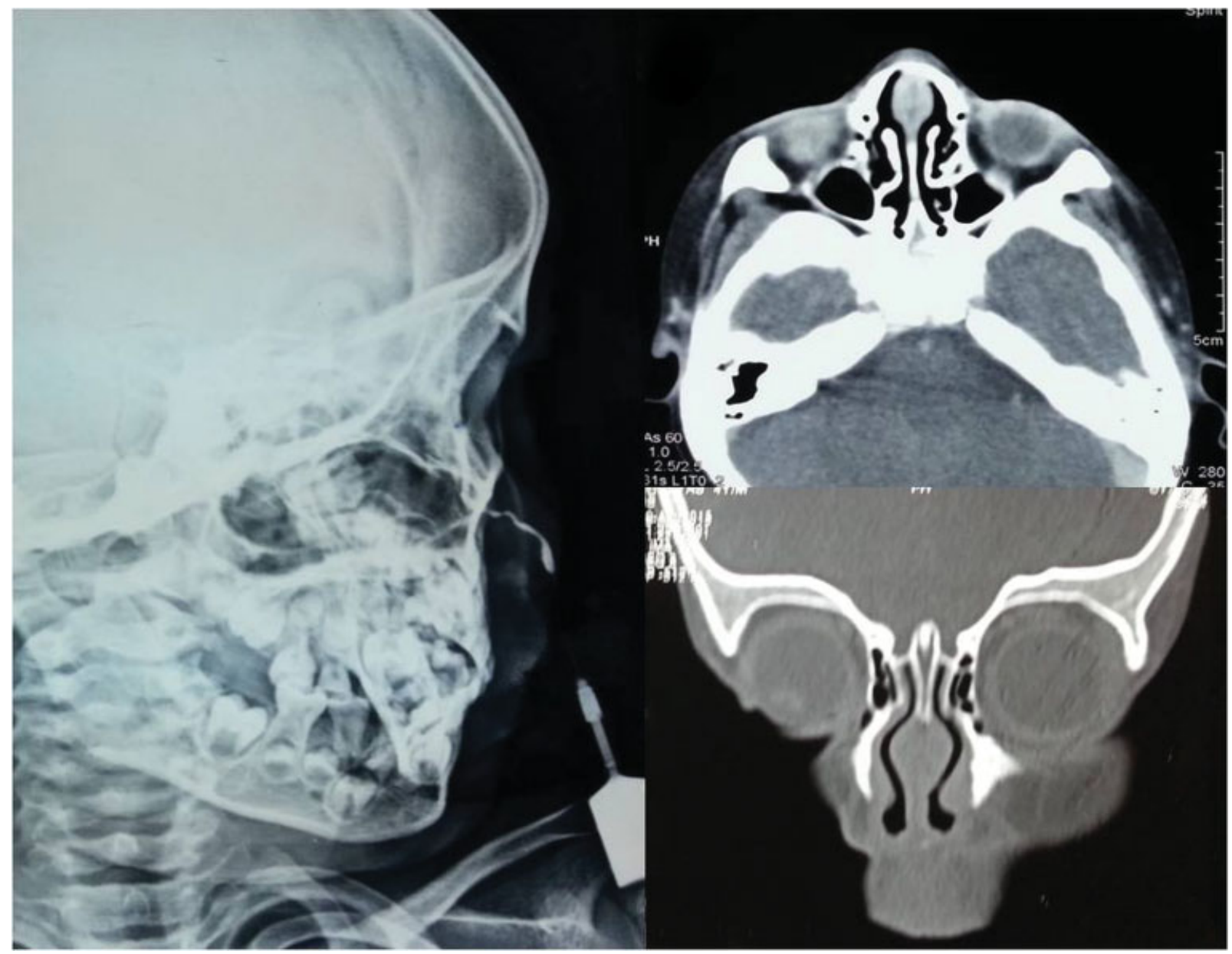

Fig. 2 Sinogram and CT scan revealing cyst with single tract going under nasal bones and evidence of a bifid crista galli. CT, computed tomography. 


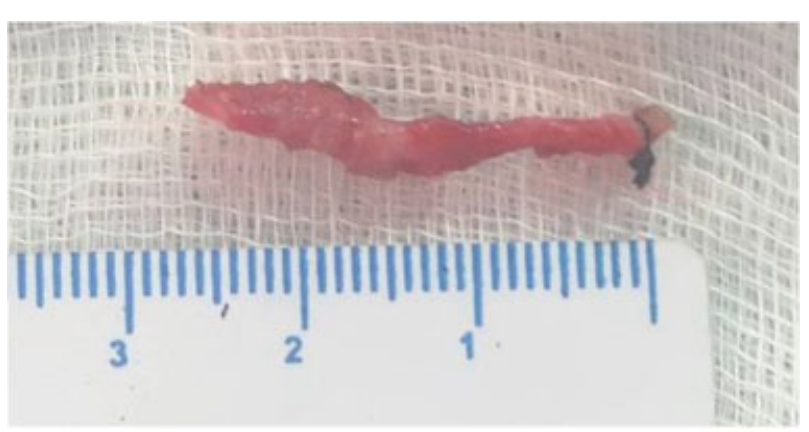

Fig. 4 Excised specimen.

Various theories of origin have been proposed. The exact pathogenesis involves the incomplete obliteration of neuroectoderm in the developing frontonasal region. ${ }^{1,11}$ Earlier theories such as superficial sequestration by Bland-Sutton and trilaminar theory by Littlewood can explain the formation of nasal dermoid, but not the intracranial extension. The most widely accepted theory is that of Grunwald, termed as the prenasal theory by Pratt ${ }^{2}$ and cranial theory by Bradley. ${ }^{12}$ Normally, during the development of frontal and nasal bones, the prenasal space is formed, through which a small projection of dura extends to the skin. As the nasal process of the frontal bone grows, the skin and dura become separated, and the projection of the dura normally obliterates, thereby severing the neuroectodermal connection. According to the prenasal or the cranial theory, as the dura mater recedes from the prenasal space, it may pull the nasal ectoderm upward and inward to form a sinus or a cyst. However, if the dura fails to obliterate, it results in intracranial communication. ${ }^{2}$ Sessions was the first to coin the term nasal dermal sinus cyst to include all lesions containing ectoderm (stratified squamous epithelium) and mesoderm (adnexal structure) located in the nose. ${ }^{1}$

Nasal dermoids are usually diagnosed within 3 years of age. Most common presentations include a midline mass,

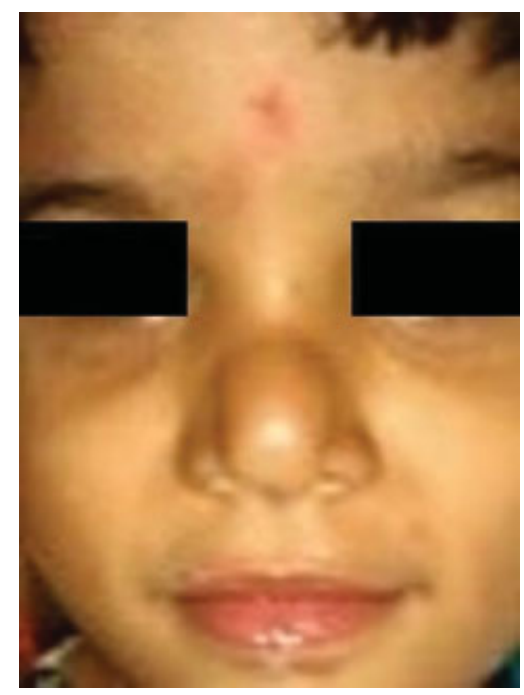

Fig. 5 Apperance after 2 years of follow-up. most commonly along the dorsum with or without sinus opening. Intermittent discharge of sebaceous material and recurrent infection is common. Hair protruding through a punctum is pathognomonic for nasal dermoid. ${ }^{13}$ Progressive enlargement of a nasal dermoid can cause soft tissue and skeletal deformity, recurrent local infection, meningitis, and brain abscess. There is no correlation between the initial presentations of nasal dermoid with intracranial extension. Bradley ${ }^{12}$ noted that most dermoids were confined to the superficial nasal area (61\%), although extension to the nasal cartilage (16\%), cribriform plate (12\%), nasal bone (10\%), and ethmoidal air cells (1\%) was noted. The incidence of intracranial extension of dermoids ranges from 4 to $45 \%$. Intracranial extension of the tract most often passes through the foramen cecum or cribriform plate to the base of the frontal fossa and adheres to the leaves of the falx cerebri extradurally. ${ }^{13}$

Imaging modalities include plain radiograph, sonogram, and CT and MRI scans. The plain radiographic findings include bony destruction of the glabella, a large infrafrontal-interethmoidal cystic space, widening of the nasal vault, and increased intraorbital distance. ${ }^{14}$ Sinogram is exclusively performed if the intracranial extension is not suspected after preliminary CT or MRI and to find out if the tracts are single or multiple for the easiness of excision of tracts. Cranial CT is valuable to show the bone alterations such as widening of the foramen cecum, ipsilateral osseous defect in the cribriform plate, and bifid or eroded crista galli, thereby helping in diagnosis. Disadvantages of CT are expectation of ionized radiation and interpretation problems because of the unseparated crista galli and perpendicular plate of the ethmoid bone in infants younger than 1 year. MRI has higher resolution for soft tissue, and therefore any intracranial extension can be clearly delineated. Both CT and MRI are complementary to each other.

Surgery is the mainstay of treatment, and the approach depends on the location of the cyst/sinus and the presence or absence of intracranial extension. The cutaneous punctum is removed in continuity with the tract and/or the cyst by making an elliptical incision around the sinus opening. Although various approaches, such as the midline vertical, transverse, lateral rhinotomy, inverted U, external rhinoplasty, and endoscopic approaches, are described for the excision of these lesions, one with concerns over the cosmetic results of facial surgery has to be chosen especially in young children.

Open rhinoplasty has been advocated by many authors as the preferred method for extracranial excision, the reasons being good exposure to the nasal dorsum, good esthetic results, and simultaneously allowing the reconstruction of the nasal dorsum. ${ }^{5,6,15,16}$ Even dermoids with minimal intracranial extension can be excised readily using a combined coronal-open rhinoplasty approach. ${ }^{8}$ This approach has limits, especially when dissecting superiorly in the prenasal space deep to the nasal bones, where visualization is limited and the need for wide undermining of the nasal tip and dorsum may affect subsequent nasal growth, as is evident in the present case after follow-up of 2 years. ${ }^{17}$ 


\section{Conclusion}

Although NDSCs are uncommon and complex lesions, they can be managed successfully with careful clinical assessment, preoperative radiograph CT and MRI scans, and appropriate surgery. Open rhinoplasty, either alone or combined with a direct excision, should be the preferred approach in young children with extracranial lesions, as it offers the opportunity to correct the position of the alar cartilages, which are often splayed by a lesion at the nasal tip, and one can achieve good aesthetic and functional results.

\section{Conflict of Interest}

None.

Funding

None.

\section{References}

1 Sessions RB. Nasal dermal sinuses-new concepts and explanations. Laryngoscope 1982;92(8 Pt 2, Suppl 29):1-28

2 Pratt LW. Midline cysts of the nasal dorsum: embryologic origin and treatment. Laryngoscope 1965;75:968-980

3 Littlewood AHM. Congenital dermoid cysts and fistulae. Br J Plast Surg 1961;14:169-175

4 Yavuzer R, Bier U, Jackson IT. Be careful: it might be a nasal dermoid cyst. Plast Reconstr Surg 1999;103(07):2082-2083
5 Denoyelle F, Ducroz V, Roger G, Garabedian EN. Nasal dermoid sinus cysts in children. Laryngoscope 1997;107(06):795-800

6 Rohrich RJ, Lowe JB, Schwartz MR. The role of open rhinoplasty in the management of nasal dermoid cysts. Plast Reconstr Surg 1999;104(05):1459-1466, quiz 1467, discussion 1468

7 Kelly JH, Strome M, Hall B. Surgical update on nasal dermoids. Arch Otolaryngol 1982;108(04):239-242

8 Bilkay U, Gundogan H, Ozek C, et al. Nasal dermoid sinus cysts and the role of open rhinoplasty. Ann Plast Surg 2001;47(01):8-14

9 Rahbar R, Shah P, Mulliken JB, et al. The presentation and management of nasal dermoid: a 30-year experience. Arch Otolaryngol Head Neck Surg 2003;129(04):464-471

10 Hanikeri M, Waterhouse N, Kirkpatrick N, Peterson D, Macleod I. The management of midline transcranial nasal dermoid sinus cysts. Br J Plast Surg 2005;58(08):1043-1050

11 Weiss DD, Robson CD, Mulliken JB. Transnasal endoscopic excision of midline nasal dermoid from the anterior cranial base. Plast Reconstr Surg 1998;102(06):2119-2123

12 Bradley PJ. The complex nasal dermoid. Head Neck Surg 1983;5 (06):469-473

13 Wardinsky TD, Pagon RA, Kropp RJ, Hayden PW, Clarren SK. Nasal dermoid sinus cysts: association with intracranial extension and multiple malformations. Cleft Palate Craniofac J 1991;28(01):87-95

14 McQuown SA, Smith JD, Gallo AE Jr. Intracranial extension of nasal dermoids. Neurosurgery 1983;12(05):531-535

15 Posnick JC, Bortoluzzi P, Armstrong DC, Drake JM. Intracranial nasal dermoid sinus cysts: computed tomographic scan findings and surgical results. Plast Reconstr Surg 1994;93(04):745-754, discussion 755-756

16 Morrissey MS, Bailey CM. External rhinoplasty approach for nasal dermoids in children. Ear Nose Throat J 1991;70(07):445-449

17 Verwoerd CD, Urbanus NA, Nijdam DC. The effects of septal surgery on the growth of nose and maxilla. Rhinology 1979;17 (02):53-63 